\title{
Editorial
}

\section{Poder monetório internacional: uma tentativa de construção conceitual em Economia Política Internacional}

\author{
International monetary power: an attempt of concept formation \\ in International Political Economy \\ DOI: 10.5752/P.1809-6182.2016v13.n3.pl63
}

Pedro Romero Marques ${ }^{1}$

\section{RESUMO}

Recebido em: 27 de julho de 2016 Aprovado em: 19 de outubro de 2016

Este trabalho tem como objetivo principal a discussão do conceito de "poder monetário internacional" utilizado pela literatura de Economia Politica Internacional. Partindo da metodologia de construção de conceitos proposta por Sartori $(1970,1984)$ e empregada por Weyland (2001) e Fonseca (2015), procura-se, a partir de seu tratamento em abordagens da área, consolidar uma definição de poder monetário internacional nos moldes de um conceito clássico. Como resultado, obtém-se que poder monetário consiste na capacidade da moeda de alterar condiçôes econômicas internacionalmente de maneira a atingir os objetivos politicos de seu Estado emissor, garantindo o minimo possivel de prejuizos sobre sua relevância para a economia internacional e o máximo possivel de resistência às pressóes relacionadas ao ajuste do balanço de pagamentos por parte do Estado emissor. Conclui-se, dessa forma, que o núcleo-duro do conceito é formado por cinco atributos: Estado emissor de moeda, objetivos politicos, grau de internacionalizaçâo da moeda, efeitos macro e microeconômicos e capacidade de resistir a pressóes de ajuste no balanço de pagamentos.

Palavras-chave: Poder monetário internacional. Moeda. Estado

\begin{abstract}
The article aims to discuss the concept of "international monetary power" employed by International Political Economy literature. By following the concept formation methodology proposed by Sartori (1970, 1984) and employed by Weyland (2001) and Fonseca (2015), it proposes a definition for "international monetary power" along the lines of a classic concept. As a result, it is argued that international monetary power consists on the currency's ability to change economic conditions internationally in order to achieve the political aims of its issuer state, ensuring the highest ability as possible for its issuer state's to resist the pressures related to balance of payments adjustment and the least negative effects over the currency's relevance to international economy. It follows, therefore, that the concept hard core has five attributes: an issuer state, political aims, the currency's degree of internationalization, macro and microeconomic effects and the ability to resist the pressures of adjustment over the balance of payments.
\end{abstract}

Keywords: International monetary power. Currency. State.

1. Mestrando em Estudos Estratégicos Internacionais (UFRGS), graduando em Ciências Econômicas (UFRGS) e Bacharel em Relaçóes Internacionais (UFRGS). 


\section{Introdução}

A Economia Política Internacional (EPI) consiste em uma disciplina acadêmica formal relativamente recente, surgida da tentativa de atuar como denominador comum das áreas de Economia e de Relações Internacionais no contexto pós Segunda Guerra Mundial (COHEN, 2008). É compreensível, portanto, que o campo apresente-se ainda em formação e revele um contínuo esforço em definir agendas de pesquisa, consolidar abordagens teórico-metodológicas e construir conceitos capazes de funcionar como elementos conectores da multidisciplinaridade da área, ou seja, de fundamentar um léxico comum aos pesquisadores do campo.

Por isso, são valiosas as tentativas de discutir, definir e operacionalizar conceitos utilizados pela literatura da área. Isso permite fortalecer a EPI como campo de estudo, uma vez que refina e qualifica as perguntas e hipóteses debatidas e concede progressividade ao programa de pesquisa. Assim sendo, este trabalho tem como objetivo retomar a discussão acerca da moeda e sua utilização como um instrumento de poder, tendo como foco a qualificação do conceito de "poder monetário internacional", cuja utilização se dá de maneira ampla pela literatura da área² .

O trabalho inspira-se na metodologia proposta por Sartori $(1970,1984)$ e operacionalizada por Weyland (2001) e por Fonseca (2015) para, a partir da observação do emprego do termo "poder monetário internacional", promover uma tentativa de construção de um conceito clássico ${ }^{3}$. Entende-se por clássico o tipo de conceito que não pretende atingir uma definição ideal, desejável ou abstrata, mas sim cujo foco está na aproximação da realidade prática

2 Em inglês, "international monetary power". Por praticidade, adota-se o termo "poder monetário" ao invés de "poder monetário internacional" em certas partes deste artigo, sem prejuízo para o sentido do conceito.

3. Weyland (2001), com base em Sartori (1970, 1984) discute o conceito de "populismo" e Fonseca (2015), "desenvolvimentismo", ambos no contexto latino-americano. por meio da formação de um núcleo-duro que inclua apenas atributos indispensáveis. Os benefícios desse esforço advêm da possibilidade de compreender o poder monetário internacional como um conceito capaz de ser amplamente verificável em casos específicos, sendo, portanto, passível de utilização em futuras pesquisas como instrumento de análises e comparaçóes. Dessa forma, procura-se inverter uma tendência expressa em abordagens clássicas tanto das Relações Internacionais quanto em Economia de negligenciar a relação entre moeda e poder no sistema internacional (ANDREWS, 2006).

Este artigo se divide em três seçōes para além da introdução e das consideraçôes finais. A primeira seção consiste na discussão da metodologia empregada com atenção específica para o campo de estudo. A segunda, por sua vez, diz respeito à retomada das abordagens de EPI que discutem o conceito de poder monetário internacional, de maneira a identificar os atributos que o qualificam. Por fim, a última seção propóe uma tentativa de apreciar e construir um conceito nos moldes clássicos para poder monetário internacional, realizando a aproximação entre a metodologia proposta e a literatura verificada.

\section{Uma nota metodológica: construção conceitual e economia política internacional}

A discussão acerca do conceito de poder monetário internacional inicia a partir da identificaçăo de dois problemas essenciais que estão inter-relacionados. $\mathrm{O}$ primeiro, inerente à EPI, consiste no fato de que a aproximação entre as dinâmicas política e econômica no sistema internacional se dá por uma quantidade considerável de atores (Estados, instituiçôes internacionais, agentes privados) que, ao buscar seus objetivos, interagem de forma a gerar efeitos de impactos diversos sobre a estrutura do sistema. 
O segundo elemento, que advém especialmente dessa realidade, consiste em uma aparente dificuldade da literatura em simplificar esse grau de complexidade na construçáo de conceitos bem sedimentados. Nesse sentido, vale lembrar a ideia de "escada da abstraçáo", instrumento ilustrativo utilizado para a construção de conceitos em Ciência Política apresentada por Sartori (1970). Ela consiste em uma escala que relaciona o grau de abstração dos conceitos utilizados com suas propriedades lógicas e empíricas, bem como com seu propósito e escopo em termos de pesquisas comparativas. Em termos gerais, tal escala esquematiza a relação existente entre o grau de abstração dos conceitos empregados e o dilema existente entre a abrangência versus a especificidade desse conceito. A dizer, uma maior abstração indica uma maior capacidade de abrangência de casos que, em contrapartida, indica uma menor especificidade das propriedades desse conceito aplicadas a tais casos.

Conforme Sartori (1970), uma definição de alta abstração tende à universalização do conceito, a dizer, à construção de uma teoria global, que envolve diferentes contextos em diferentes espaços de tempo. Faz sentido, dada à complexidade da EPI, a construção de conceitos visando à universalização, de forma a abarcar elementos políticos, econômicos, sociais, entre outros ${ }^{4}$. O problema apresentado por Sartori (1970), no entanto, é que há o risco de que o grau de abstração adotado tenha efeitos sobre as propriedades e os atributos desse conceito e traga dificuldades para os propósitos específicos das pesquisas 5 . Isso incide, logicamente, na pró-

4. Conforme Weyland (2001, p.1-2), confusôes aparecem frequentemente quando diferentes especialistas se focam em diferentes atributos que definem esses conceitos. Isso consiste em um problema recorrente em conceitos que tem aplicaçôes em diversos domínios do conhecimento: político, econômico, social, entre outros.

5. Como se percebe em Sartori (1970), a construção de um conceito tem uma importante carga histórica. Em outras palavras, para continuar sendo válido, um conceito precisa ter capacidade de se adaptar e de resistir às alteraçóes da realidade, pria consideração sobre poder monetário internacional. Uma vez que a EPI motiva-se a construir compreensôes abrangentes acerca da dinâmica de poder em uma realidade internacional reconhecidamente complexa, há um alto risco de confusão conceitual, tornando difícil limitar a forma pela qual a noção de poder está expressa nos fenômenos concretos das interaçóes internacionais, como por exemplo, o uso da moeda.

De maneira mais clara, é possível exemplificar tal problema a partir de Strange (1998) e Cohen (2014), que, adotando uma concepção de poder mais universalizada, não delimitam seu estudo ao sistema monetário internacional, mas sim ao sistema internacional como um todo. Em Strange (1998), a noção de poder que incide sobre a economia política global é aplicada de forma relacional e de forma estrutural. A primeira deriva da noçáo tradicional de forçar o outro a realizar algo contra sua vontade, enquanto que a segunda consiste no "poder de moldar e determinar a estrutura da economia política global dentro de outros Estados, suas instituiçóes políticas, seus empreendimentos econômicos e (não menos importante) a forma como seus cientistas e outros profissionais têm de operar" (STRANGE, 1998, p. 24-25, traduçáo nossa) ${ }^{6}$. A partir dessa definição dual e ampla, Strange (1998) considera o sistema internacional um sinônimo de economia política global e demonstra o alto grau de abstração de sua compreensão, tornando difícil a percepção de propriedades mais específicas como o papel da moeda.

Para Cohen (2014), as categorias de Strange (1998) não seriam capazes de capturar toda a reali-

garantindo sua utilização e aplicabilidade no tempo presente. Não raro essas alterações provocam distorções que levam as definiçóes rumo à perda de valor conceitual (SARTORI, 1970; FONSECA, 2015)

6. the power to shape and determine the structure of the global political economy within which other states, their political institutions, their economic enterprises and (not least) their scientist and other professional people have to operate 
dade atual das finanças internacionais. Ao longo da abordagem, Cohen (2014) remete às perspectivas teóricas acerca da dinâmica de poder internacional, indicando que sua argumentação está voltada para a construção de uma reflexão geral sobre a estrutura de poder global. Subitamente, porém, o autor passa a empregar o termo "poder monetário" para se referir a poder, avaliando, porém, o sistema monetário internacional: "a criação do euro; os desequilíbrios de pagamentos globais e a globalização dos mercados financeiros" (COHEN, 2014, p.12, tradução nossa) ${ }^{7}$. Percebe-se, nesses casos, uma dificuldade em limitar o escopo de análise da pesquisa, fato conectado diretamente com as barreiras derivadas da construçáo conceitual. Esses dois exemplos, que serão retomados de forma mais direcionada na seção seguinte, ajudam a ilustrar a dificuldade de se trabalhar com conceitos universais com alto nível de abstração. A crítica não se desenha na tentativa de eliminar a universalização das explicaçóes, mas chama a atenção para a necessidade de construção de conceitos mais aplicáveis na observação da realidade concreta.

Embora se reconheça sua importância, este trabalho se isenta da participação no debate que concerne à discussão do que é poder em EPI. Tem-se que não é necessário construir um modelo ideal da relação entre os termos de "poder" e "moeda" de forma a conceber um significado para "poder monetário internacional", já comumente empregado. A tentativa de fazê-lo poderia resultar em um conceito de poder monetário incapaz de atender as demandas analíticas que dão origem à própria discussão acerca da necessidade de sua definição. Por isso, conforme justifica Fonseca (2015), o trabalho de escrutínio do conceito, da forma como ele é representado tanto na literatura da área quanto no estudo de casos específicos, funciona como instrumento capaz de trazer seu significado de forma mais tangível.

\footnotetext{
7 (1) the creation of the euro; (2) wide global payments imbalances; and (3) the globalization of financial markets.
}

Assim sendo, vale atentar para os três tipos de conceitos enumerados por Sartori (1984) e explorados por Weyland (2001) e Fonseca (2015). O primeiro tipo consiste no conceito formado por acumulação. Essa categoria parte da observação e da identificação, nos diversos domínios que tratam do objeto, das características que, somadas, qualificam-no, formando um núcleo-duro expandido e bem definido. Nesse caso, o núcleo-duro contém todas as especificidades atribuídas ao conceito, o que na prática indica uma perda de sua abrangência. A vantagem dessa categoria está em evitar a inclusão de casos que possam parecer remetentes à definição conceitual, mas que consistem em situaçóes não aplicáveis. A desvantagem, no entanto, está na limitação de sua aplicação prática, ou seja, no obstáculo que esse tipo de conceito representa para domínios que possuem concepçóes diferentes da realidade (FONSECA, 2015; WEYLAND, 2001).

O segundo tipo, o conceito radial, representa a flexibilizaçáo do conceito formado por acumulação. Um conceito radial ocorre quando há o relaxamento do núcleo-duro específico, possibilitando que "qualquer caso que apresente uma das características pode em tese ser subsumido ou incluído no conceito" (FONSECA, 2015, p. 12). Nesse sentido, o conceito ganha em abrangência e perde em especificidade, evitando a desconsideração de casos potenciais. Para Weyland (2001), há a vantagem de contemplar os diversos domínios atingidos pelo conceito, podendo adaptá-lo a diferentes perspectivas teóricas. Isso acaba, porém, beneficiando a formação de subcategorias que, em última instância, assumem significados amplamente distintos e tornam o conceito vago (FONSECA, 2015; WEYLAND, 2001).

O terceiro tipo, por sua vez, consiste no conceito clássico, que funciona como uma tentativa de equilibrar o grau de abrangência e o grau de especificidade a partir de um mínimo aceitável. Isso tam- 
bém se dá pela formação de um núcleo-duro, mas que, ao contrário do conceito por acumulação, abre mão de abarcar a totalidade das características possíveis. Ele se restringe a aglomerar atributos principais e tem seu foco em certo domínio, o que lhe fornece a capacidade de incluir casos que convirjam em características fundamentais, mas que guardam sua diferenciaçấo por meio de suas especificidades originárias de diversos domínios (FONSECA, 2015; WEYLAND, 2001).

A maior vantagem do conceito clássico consiste na sua função prática para a atividade de pesquisa: "eles incitam os acadêmicos a investigar empiricamente as conexóes entre as características que definem o conceito e outros atributos hipotéticos, ao invés de decretá-los por definição, como fazem os conceitos cumulativos, ou deixá-los em aberto, como fazem os conceitos radiais" (WEYLAND, 2001, p.3 ${ }^{8}$. A dificuldade, no entanto, reside no processo de definição desse núcleo comum, que passa pela identificação das características necessárias e suficientes à fundamentação do conceito e, principalmente, pela diferenciaçáo de outros aspectos inerentes ao próprio conceito como causas, condiçôes e consequências (FONSECA; 2015; SARTORI, 1984; WEYLAND, 2001).

\section{O poder monetório internacional na economia política internacional: concepções e aplicações}

Esta seção tem como objetivo retomar, na literatura que relaciona poder e moeda, as principais tentativas de conceituação e caracterização do poder monetário internacional. Tal etapa importa porque é a partir

8. They thus prompt scholars to investigate empirically the connections between definitional characteristics and other hypothesized attributes, rather than decree them by definitional fiat, as cumulative concepts do, or leave them open, as radial concepts do. da retomada das maneiras pelas quais o conceito é comumente utilizado pela comunidade acadêmica que se torna capaz de derivar um núcleo duro conceitual.

Embora se isente aqui de discutir a ideia de poder de uma forma generalizada, é imprescindível ressaltar a tentativa de Strange (1998) em conceber uma visão global da economia política, relacionada à dinâmica de poder existente entre os Estados, às instituiçôes e aos diversos outros agentes no cenário internacional. A definição de Strange (1998) chama a atenção para o exercício do poder para além da relação entre Estados, ressaltando os impactos gerais sobre os agentes econômicos e políticos, uma perspectiva interessante, embora tenha sido amplamente criticada por outros acadêmicos da área pela falta de precisão (HELLEINER, 2006, p.74). Mesmo assim, tal concepçáo de que o exercício de poder dos Estados resulta em efeitos indiretos e mesmo não intencionais acaba por se repetir com frequência nas tentativas de conceituar poder monetário internacional.

Ao falar de poder monetário internacional, Cohen $(2005,2010,2014)$ critica uma visão instrumental de poder, reconhecendo a importância sistêmica ressaltada por Strange (1998) através do reconhecimento de diferentes facetas de manifestação:

No contexto das relaçôes monetárias internacionais, a maioria das análises acerca do poder tendem a focar em manifestaçóes claras da influência a níveis macro ou micro - a habilidade dos governos de desempenhar um papel autoritário, por exemplo, em gerenciamento de crises, políticas de regulaçáo financeira ou a oferta de financiamento para os pagamentos. Mas para verdadeiramente entender o poder monetário, é preciso ir além dessas manifestaçôes de forma a enxergar a origem dessas habilidades. Tal fato demanda a clarificação de dois elementos principais: a definição relevante de poder e as naturezas do ambiente onde os Estados operam (COHEN, 2011, p. 160, tradução nossa) ${ }^{9}$.

9. In the context of international monetary relations, most power analyses tend to focus on overt manifestations of influence at a micro or macro level - the ability of a government to play an authoritative role in, say, crisis management or finan- 
Conforme o autor, o poder monetário teria duas faces: a autonomia, que consiste na habilidade de um Estado de agir de forma livre, evitando os constrangimentos advindos de outros atores e a influência que, por sua vez, poderia ser enxergada como ativa ou passiva. A primeira consistiria em um ato deliberado de coerção, ou seja, de forçar o outro a fazer algo contra sua vontade. A última, por outro lado, seria um ato inconsciente e náo intencionado derivado inerentemente da autonomia, um subproduto indireto do poder. Embora ele mesmo afirme que há uma relação direta e proporcional entre autonomia e influência porque o poder monetário decorre de relaçóes monetárias internacionais inerentemente recíprocas, escapa de sua abordagem uma definição mais sólida de poder monetário internacional, uma vez que ele insiste em segmentar o conceito por meio de subcategorias.

Em termos mais específicos, para Cohen (2011), o poder monetário estaria relacionado com a internacionalização da moeda. Quanto maior seu grau de internacionalização, maior o poder que essa moeda tenderia a adquirir no sistema monetário internacional. A medida de tal poder se daria pelas vantagens concedidas aos Estados emissores da moeda, sendo expressa pelos ganhos com senhoriagem, alta flexibilidade para manobras de política econômica, boa reputação internacional e ampla capacidade de adquirir empréstimos e financiamentos internacionais. Ao partir dessas vantagens, o autor analisa os papeis da moeda no cenário privado e público internacional e conclui que mais do que sua participação em investimentos ou em fluxos de comércio, uma moeda adquire sua importância no sistema monetário por meio de seu valor como reserva de valor internacional (COHEN, 2011).

cial regulatory politics or the supply of payments financing. But to truly understand monetary power, we have to behind these manifestations to see where such abilities come from. That demands clarification of two key items: the relevant definition of power and the natures of the environment in which states operate.
Embora reconheça que a internacionalização das moedas consista amplamente em um fenômeno de mercado, ou seja, reflexo das preferências dos agentes econômicos internacionais, enfatiza que, sendo o monopólio de emissão de moeda uma função atribuída aos Estados, o poder emanado dessa atividade reflete-se, portanto, de maneira direta em relaçôes interestatais. Nesse sentido, o autor chama atençâo para o fato de que o exercício do poder monetário envolve tanto objetivos políticos quanto econômicos dos Estados, sendo ele expresso nos âmbitos dos mercados financeiros internacionais, do comércio internacional e das reservas internacionais detidas pelos bancos centrais (COHEN, 2011).

O papel exercido pelas moedas nesses âmbitos seria indicativo da autonomia monetária dos países, que se refletiria em influência no sistema monetário internacional, seja ela deliberada ou não. A existência de autonomia monetária forneceria independência política para os Estados frente a assuntos monetários, ou seja, concederia a capacidade de evitar os custos do ajuste do balanço de pagamentos ou transferir esses custos para outros atores internacionais. Para Cohen (2011), esse é o componente central do poder monetário, fruto de uma vontade política deliberada, embora seus reflexos estejam imbuídos no exercício mundial do poder monetário de forma indireta e não intencional.

$\mathrm{Na}$ tentativa de restringir a compreensão do poder monetário à manifestação exclusiva das relações monetárias, Andrews (2006) adota uma posição deliberadamente centrada no papel do Estado e na premissa de que "o poder monetário internacional existe quando o comportamento de um estado muda graças a seu relacionamento monetário com outro estado" (ANDREWS, 2006, p. 2, tradução nossa) ${ }^{10}$. Para Andrews (2006) tais relações monetárias podem

10. International monetary power exists when one state's behavior changes because of its monetary relationship with another state. 
alterar as políticas dos Estados de forma direta ou indireta, conservando a noção proposta por Cohen (2014) e Strange (1998) de uma faceta indireta do poder monetário, porém limitando às condiçóes desse poder às relaçóes monetárias, um passo simples, porém importante na definição do conceito.

O ponto mais relevante na abordagem de Andrews (2006) diz respeito ao fato de que o poder monetário se reflete tanto no nível macro, por meio dos Estados, quanto no nível micro, em dimensóes não estatais, mesmo sendo ele um exercício que surge da vontade política estatal. No nível macro, a discussão em torno do poder monetário teria como referência a questão da necessidade de ajuste do balanço de pagamentos e sobre que país recairia a responsabilidade de realizá-lo: "Custos de ajuste não são uniformes; alguns são contínuos, outros transitórios. Poder monetário no nível macro consiste na capacidade tanto de atrasar o pagamento dos custos contínuos do ajuste quanto de direcionar os custos transitórios para outros países" (ANDREWS, 2006, p. 11, tradução nossa) ${ }^{11}$.

Com respeito ao nível micro, Andrews (2006) refere-se à capacidade dos entes não governamentais domésticos ou transnacionais de se beneficiar da dinâmica das relações monetárias internacionais. De forma mais específica, a dimensão micro se caracteriza pelos impactos dessas interações na rearticulação dos interesses e na reconstrução das identidades dos atores, referindo-se às vantagens que certas moedas oferecem para os objetivos de diversos agentes internacionais, sejam eles políticos ou motivados pelo lucro.

Em consonância com Andrews (2006), Kirshner (1997) assume que o poder monetário está

11. Adjustment costs are not uniform; some are continuing, others transitional. Monetary power at the macro-level consists on the capacity either to delay payment of adjustment's continuing costs or to deflect its transnational costs on to others. Different mechanisms are associated with these two capacities, each with distinctive sources. Para maiores discussões ver Cohen (2005) e Andrews (2006). relacionado à esfera de relaçóes monetárias interestatais, sendo utilizado para interferir nas escolhas e no comportamento de outros Estados. O ponto fundamental residiria, no entanto, nos objetivos que motivam o exercício do poder monetário: este seria uma forma de obter vantagens relacionadas a fins não econômicos, principalmente à política e à segurança internacional. É importante ressaltar que Kirshner (1997) não descarta a esfera econômica, tampouco desconsidera a complexidade da relação entre economia e política:

Novamente, é possível perceber sobreposiçôes aqui, mais claramente no fato de que, em longo prazo, torna-se cada vez mais difícil distinguir entre a busca da riqueza e a busca do poder. No entanto, o foco em objetivos não-econômicos não exige que as linhas explícitas de demarcação sejam identificadas, ou mesmo existam. Ele simplesmente enfatiza uma extremidade do espectro, onde os objetivos não econômicos são determinantes (KIRSHNER, 1997, p. 4, tradução nossa) ${ }^{12}$.

Isso indica que sua abordagem é resultado da tentativa de aprimorar o entendimento do conceito de poder monetário internacional e não uma desconsideração dos outros fatores que derivam do exercício de tal. Dessa forma, mais especificamente, Kirshner (1997) adota a perspectiva relacional para definir três maneiras pelas quais se dá o exercício do poder monetário, as quais seriam as bases para a construção do conceito: manipulação monetária, dependência monetária e ruptura sistêmica ${ }^{13}$.

12. Once again, there are overlaps here, most obviously in the fact that in the long run it becomes increasingly difficult to distinguish between the pursuit of wealth and the pursuit of power. However, this focus on noneconomic goals does not require that explicit lines of demarcation be identified, or even exist. It simply emphasizes one end of the spectrum, where noneconomic goals are determinant.

13. Para fins de esclarecimento, a primeira consiste em açóes tomadas para afetar a estabilidade e o valor de moedas alvo; a segunda, no fato de que uma moeda nacional mais poderosa acaba tendo um papel de liderança sobre outras moedas a ela conectadas; e, por fim, a terceira, quando há a tentativa de uma moeda de romper a ordem imposta por outra. A conclusão do autor é que o uso da moeda como instrumento de poder é 
Nota-se que Kirshner (1997) enxerga o poder monetário internacional a partir da maneira pela qual ele é utilizado, o que prejudica a consideração dos seus fundamentos. Isso se verifica na explicação de Kirshner (1997) sobre o exercício da manipulação monetária. Ao definir em que consiste tal atividade, o autor ressalta a amplitude de sua utilização securitária - desde a coerção interestatal até a desestabilização de um regime nacional. Chama atenção, todavia, que se encontram no cerne dessa instrumentalização a questão da manipulação das taxas de câmbios internacionais e, consequentemente, as dificuldades relacionadas ao equilíbrio do balanço de pagamentos, bem como implicaçôes econômicas (inflação, fuga de capital, dificuldade de atração de investimento) e interferência em projetos de desenvolvimento nacionais (KIRSHNER, 1997, p. 9). Essa relação entre objetivos, estabilidade política e fundamentos macro e microeconômicos é essencial para a compreensão do poder monetário, já que consiste em uma forte crítica às perspectivas que consideram que a economia pode ser analisada independentemente da dinâmica política. Os fins políticos podem ser obtidos, como demonstra Kirshner (1997), através da manipulação de variáveis econômicas fundamentais para a sobrevivência política de um regime.

Para além das abordagens discutidas, é possível mencionar uma ampla literatura que, embora não tenha como foco central a tentativa de conceituação de poder monetário, acaba por promover a discussão do termo como consequência direta da iniciativa de analisar outros fenômenos do sistema monetário internacional. Um exemplo disso pode ser verificado em Webb (1994) que, ao discorrer sobre as possibilidades de cooperaçáo internacional em política macroeconômica diante de diferentes graus de mobilidade de capital, faz contribuiçóes relevantes para a com-

o mais eficiente para os Estados, em comparação com outras formas de exercício de poder econômico: ajuda internacional e domínio dos fluxos comerciais e financeiros. preensão do poder monetário. Conforme o autor, o peso do ajuste do balanço de pagamentos que incide sobre os Estados no sistema monetário internacional tem sua distribuição e suas consequências fortemente condicionadas pelo exercício do poder. Nesse caso, Webb (1994) enumera algumas atribuições que trazem maior ou menor vulnerabilidade para um país diante desta dinâmica de ajuste. Para o autor, os países deficitários se encontram em posiçóes menos favorecidas na tentativa de evitar o peso do ajuste, dadas as dificuldades de países nessa situação de lidar com fuga de capitais ou com a depreciação cambial, bem como de adquirir empréstimos externos. Além disso, países maiores e menos dependentes do fluxo internacional de comércio seriam mais capazes de resistir pressóes de ajuste por meio de incentivo ao mercado interno, podendo sustentar o desequilíbrio por mais tempo. Por fim, o autor enfatiza a importância das moedas nacionais, que assumem papel de reserva e meio de troca internacional. Elas aliviam a situação de pagamentos de seus países emissores porque, ao serem atrativas aos agentes externos, são detidas internacionalmente e possibilitam, dessa forma, adquirir empréstimos externos sob um custo inferior (WEBB, 1994).

Webb (1994) deduz, a partir dessas condições, a importância do dólar para a garantia de uma posição privilegiada dos Estados Unidos no que concerne à dimensão do ajuste dos pagamentos. Conforme o autor, o dólar expande a capacidade de financiamento dos EUA, isentando a necessidade de premiar os investidores com altas taxas reais de juros, o que "sugere que os Estados Unidos estão em uma importante posição de barganha nas negociaçóes macroeconômicas internacionais, e o padrão de políticas de ajustes é capaz de confirmar tal fato" (WEBB, 1994, p. 412, tradução nossa) ${ }^{14}$.

14. All of this suggests that the United States is in a strong bargaining position in international macroeconomic negotiations, and the pattern of policy adjustments bears this out. 
Essa conclusão sobre a posição privilegiada dos Estados Unidos ao lidar com os desequilíbrios de pagamentos aponta que a discussão sobre a noção contemporânea de poder monetário está conectada ao papel do dólar como moeda hegemônica internacional, uma vez que a literatura reconhece tal fato de forma consensual.

Não cabe aqui uma apreciação da discussão sobre os aspectos da hegemonia do dólar, bem como seu potencial de sustentação e suas possibilidades de erosão, entretanto, é possível ressaltar algumas compreensóes do conceito de poder monetário construído a partir da observação do caso dos Estados Unidos. Baseando-se nas iniciativas de Strange (1998) e Cohen (2011), por exemplo, Norrlof (2014) reconhece a existência de um poder relacional - "a habilidade de mudar os custos e os benefícios das opçóes disponíveis através de força, pagamentos ou persuasão" (NORRLOF, 2014, p. 1058, tradução nossa) ${ }^{15}$ - e de um poder estrutural - ou seja, a "habilidade de moldar a estrutura de interação através de regras que modificam as opçôes dos governos e dos atores privados" (NORRLOF, 2014, p. 1061, tradução nossa) 16. Há, ainda, uma terceira face do poder, que remete às ideias e às percepçóes a partir das quais os Estados Unidos conseguiria garantir o suporte internacional ao papel desempenhado pelo dólar ${ }^{17}$.

Para cada uma dessas formas de exercício do poder, Norrlof (2014) discute o papel do dólar na fundamentação da hegemonia monetária estadunidense, mensurando capacidade de determinação,

15. [...] the ability to change the affected party's perceived costs and benefits of the available options through force, payment or persuasion.

16. [...] the ability to shape the structure of interaction through rules that modify the options of governments and private actors.

17. Mesmo que falte a Norrlof (2014) uma definição mais clara dessa face, a ideia de que, eventualmente, no sistema monetário internacional, os agentes comportam-se de acordo com os paradigmas vigentes e acabam assim por fortalecê-los, é de grande relevância para o entendimento das relaçóes monetárias internacionais. por parte dos Estados Unidos, da sua moeda nacional como meio de troca, unidade de conta e reserva de valor universal para atores públicos e privados. Apesar de ser declaradamente baseada na análise do poder do dólar, a argumentação de Norrlof (2014) não contempla uma robusta discussão sobre o conceito de poder monetário, embora o defina pela combinação entre influência monetária - o grau de utilização internacional de uma moeda - e autonomia monetária - conceito não escrutinado pela autora ${ }^{18}$. A falta de uma apreciaçáo do conceito parece contrastar com a atenção concedida as três faces do poder mencionadas acima. Mesmo assim, retiram-se de Norrlof (2014) elementos relevantes para a compreensão do conceito, como a importância de agentes públicos e privados, o exercício direto e indireto do poder, a relaçáo positiva entre internacionalização e poder monetário e, principalmente, a defesa da necessidade de um lastro na economia real para a garantia do exercício da hegemonia monetária. Isso propóe, em última instância, que as moedas necessitam de fundamentos sociais de forma a sustentar o exercício de poder monetário, originados de atributos econômicos, políticos, militares ou, como acredita Norrlof (2014), da interação entre esses âmbitos ${ }^{19}$.

18. As tentativas de compreender termos como poder monetário e hegemonia monetária a partir do caso estadunidense podem prejudicar a consolidaçáo desses termos como conceitos clássicos. A necessidade de um núcleo-duro que abarque características mais elementares possíveis requer a observação de diversas formas de manifestação do fenômeno em questão. Ao se referir a tais termos, pode ocorrer com que características superficiais ao núcleo duro sejam consideradas por serem emblemáticas no caso dos Estados Unidos, estando, porém, ausentes em outros possíveis casos.

19. A reflexão de Norrlof (2014) permite relembrar a discussão do papel da moeda em Marx. Como afirma Brunhoff (1978), uma vez que a concepção da moeda em Marx é completa e geral, ela remete às dimensóes sociais, econômicas e políticas conjuntamente. $\mathrm{Na}$ "Contribuição à Crítica da Economia Política”, Marx afirma que a moeda é fonte de poder político e que o poder monetário não pode ser confundido com poder econômico. Para ele, o poder monetário se refere ao âmbito da circulação, onde os valores já estão definidos. Sendo assim, os efeitos políticos e sociais da moeda dependem de sua natureza econômica (MARX, 1982, p. 47). 
Ao discorrer sobre as diferentes correntes que abordam as possibilidades de erosão da hegemonia do dólar, Helleiner e Kirshner (2009) discutem os benefícios para os Estados Unidos, tanto em termos de ganhos econômicos quanto em termos de exercício de poder. Os autores olham para as três funções da moeda no caso do dólar, de forma a verificar suas possibilidades de atuação internacional. A partir disso, enfatizam a capacidade de atrasar ou adiar os custos do ajuste da conta corrente como o principal exercício de poder resultante da atuação do dólar como moeda internacional. Além de aumentar a capacidade dos EUA de adquirir fundos internacionais - através das notas da Reserva Federal e dos títulos do Tesouro Nacional - com taxas de remuneração consideravelmente baixas, o grau de internacionalização da moeda e sua demanda internacional sustentam os desequilíbrios de pagamentos em um contexto de taxa flexível de câmbio. Conforme os autores, no momento em que o dólar perde valor frente a outras moedas internacionais, os títulos mencionados também perdem valor. Os EUA, portanto, veem a redução da quantia a pagar, valor esse que é compensado por meio de flutuações cambiais internacionais. Ademais, Helleiner e Kirshner (2009) enfatizam as vantagens microeconômicas do papel internacional do dólar, como a redução dos custos e riscos para firmas estadunidenses, e o aumento na competitividade dos bancos nacionais em mercados financeiros que tem o dólar como moeda base.

Por fim, vale atentar para a seguinte afirmativa: "Da mesma forma, como governos estrangeiros acumulam reservas em dólar, eles adquirem um interesse na estabilidade e no valor da moeda, de maneira em que pode haver o incentivo de certa identificação de seus interesses com os dos Estados Unidos" (HELLEINER; KIRSHNER, 2009, p. 6 , tradução nossa) ${ }^{20}$. Ao indicar que o poder mo20. Similarly, as foreign governments accumulate dollar re- netário dos EUA vai além de sua influência direta porque pressupóe que há uma adequação internacional às regras vigentes, tal afirmação retoma a noção de um exercício de poder indireto no sistema monetário internacional.

Ainda nesse espectro, vale mencionar o argumento de Drezner (2010), para quem a moeda de reserva internacional é um pré-requisito de poder monetário no que concerne à economia política internacional. Conforme Drezner (2010), dentre os benefícios dessa condição para o país emissor da moeda podem ser enumerados a redução dos custos de transação nas trocas internacionais e os ganhos com senhoriagem, embora os principais benefícios sejam de natureza política, no caso dos Estados Unidos, a habilidade de seu governo de emitir dívida denominada na sua própria moeda. $\mathrm{O}$ autor ainda enfatiza que o fato dos Estados Unidos serem detentores da moeda de reserva internacional são a causa e a consequência de sua hegemonia monetária, porque lhe fornece capacidade de repassar os custos do ajuste no balanço de pagamentos para outros países.

Finalmente, não se pode deixar de pontuar uma abordagem que reflete sobre o poder monetário por uma lógica além daquela relacionada ao Estado. Como exemplo, Aronson (1978) chama a atenção para a questão dos bancos e como esses atores não-estatais acabam tendo capacidades de restringir as opçóes políticas dos Estados. A lógica de Aronson (1978) reconhece o papel dos governos e dos atores privados no sistema monetário internacional, porém concede aos bancos o poder de definir, em maior ou menor grau, as decisóes políticas dos governos, restringindo sua autonomia em relação a questóes como os ajustes no balanço de pagamentos através das taxas de câmbio e do gerenciamento de reservas. $\mathrm{O}$ poder adquirido pelos ban-

serves, they acquire an interest in the stability and value of the currency in ways that may encourage a certain identification of their interests with those of the United States. 
cos na ótica apresentada por Aronson (1978) indica que os Estados estão constrangidos por uma realidade internacional e doméstica que pode ter efeitos sobre a capacidade de exercer poder monetário.

\section{O poder monetório internacional como conceito clássico ${ }^{21}$}

Como mencionado previamente, a noção de conceito clássico remete à busca pelo equilíbrio entre a abrangência e a especificidade de sua aplicação, tendo como objetivo a consideraçáo do núcleo duro formado por atributos básicos necessários, que permite ao conceito servir como instrumento de análise sem prejuízo a sua própria essência. Sendo assim, a retomada da literatura realizada permitiu a identificação de onze atributos que, ao longo das nove perspectivas, despontam como potenciais elementos constituintes do conceito de poder monetário internacional. É inegável que muitos desses atributos, dado o caráter complexo das relaçôes entre economia e política no âmbito internacional, estão intrinsecamente relacionados, o que dificulta concebê-los como atributos individuais. Todavia, faz parte do processo de construção teórica a tentativa de isolar variáveis de modo a entender sua relevância para o todo, o que é observável nas próprias abordagens discutidas, justificando a apresentação aqui proposta.

Dessa forma, o Quadro 01 resume a aparição

21. Reconhecem-se as dificuldades existentes nesse processo de construção conceitual. A primeira delas é o tamanho da amostra utilizada. Não obstante seja formada por nove perspectivas, ela consiste em uma pequena parte do que existe na literatura contemporânea e se restringe a estudos realizados em língua inglesa. Outra restrição se dá pela ausência de casos mais específicos que possam levantar questóes acerca do poder monetário internacional para além da moeda hegemônica, olhando para dimensôes regionais de dinâmicas monetárias. Por fim, cita-se a responsabilidade do autor em montar, a partir da revisão da bibliografia, um conceito de poder monetário internacional que, em última instância, vai inevitavelmente corresponder, mesmo que minimamente, ao seu entendimento acerca das relaçóes monetárias internacionais. dos onze atributos relacionados ao exercício do poder monetário internacional de acordo com os autores trabalhados.

Partindo, portanto, da presença dos atributos nas abordagens verificadas chega-se a um conceito clássico de poder monetário internacional, elaborado a partir da seguinte definição: poder monetário internacional consiste na capacidade da moeda de alterar condições econômicas internacionalmente de maneira a atingir os objetivos políticos de seu Estado emissor, garantindo o mínimo possível de prejuízos ao grau de internacionalizaçáo da moeda na economia internacional e o máximo possível de resistência às pressôes relacionadas ao ajuste do balanço de pagamentos para seu Estado emissor. Nesse sentido, o núcleo-duro necessário para a existência de poder monetário consistiria em cinco atributos principais: Estado emissor de moeda, objetivos políticos, grau de internacionalização da moeda, efeitos macro e microeconômicos e capacidade de resistir a pressóes de ajuste no balanço de pagamentos.

Cabe, a seguir, analisar as razões da inclusão e da exclusão de certos elementos no núcleo-duro e na definiçấo de poder monetário internacional, uma vez que tais atributos devem compor o conceito sem suscitar contradiçôes latentes. Em primeiro lugar, como a própria denominação indica, poder monetário internacional remete ao papel desempenhado pela moeda globalmente, sendo um consenso na literatura que sua dimensão está relacionada ao grau de internacionalização da moeda. Em outras palavras, a moeda em questão precisa ser relevante como meio de troca, unidade de conta e reserva de valor para além de seu âmbito doméstico para indicar a existência de poder monetário internacional. Não há dúvida de que o grau de internacionalização monetária deriva do processo de desenvolvimento das economias nacionais e de decisões políticas, deliberadas ou não, de incentivar o uso dessas moedas 
Quadro 01 - Atributos do Poder Monetório Internacional

\begin{tabular}{|c|c|c|c|c|c|c|c|c|c|}
\hline $\begin{array}{c}\text { Poder } \\
\text { Monetário } \\
\text { Internacional }\end{array}$ & $\begin{array}{c}\text { Aronson } \\
(1978)\end{array}$ & $\begin{array}{l}\text { Webb } \\
\text { (1994) }\end{array}$ & $\begin{array}{c}\text { Kirshner } \\
(1997)\end{array}$ & $\begin{array}{c}\text { Strange } \\
(1998)\end{array}$ & $\begin{array}{l}\text { Cohen } \\
(2010) \\
(2014)\end{array}$ & $\begin{array}{l}\text { Andrews } \\
(2006)\end{array}$ & $\begin{array}{c}\text { Helleiner } \\
\text { Kirshner } \\
(2009)\end{array}$ & $\begin{array}{c}\text { Drezner } \\
(2010)\end{array}$ & $\begin{array}{l}\text { Norrlof } \\
(2013)\end{array}$ \\
\hline $\begin{array}{c}\text { Tem o poder } \\
\text { público como } \\
\text { agente principal } \\
\text { (Estado) }\end{array}$ & & $X$ & $\mathrm{X}$ & $\mathrm{X}$ & $X$ & $X$ & $X$ & $X$ & $\mathrm{X}$ \\
\hline $\begin{array}{c}\text { Tem outro } \\
\text { agente principal } \\
\text { (não publico) }\end{array}$ & $\mathrm{X}$ & & & & & & & & \\
\hline $\begin{array}{l}\text { Afeta o âmbito } \\
\text { micro }\end{array}$ & $\mathrm{X}$ & $\mathrm{X}$ & $\mathrm{X}$ & $\mathrm{X}$ & $\mathrm{X}$ & $X$ & $\mathrm{X}$ & $\mathrm{X}$ & $\mathrm{X}$ \\
\hline $\begin{array}{l}\text { Afeta o âmbito } \\
\text { macro }\end{array}$ & $\mathrm{X}$ & $\mathrm{X}$ & $\mathrm{X}$ & $X$ & $\mathrm{X}$ & X & $\mathrm{X}$ & $\mathrm{X}$ & $\mathrm{X}$ \\
\hline $\begin{array}{l}\text { Objetivos } \\
\text { políticos }\end{array}$ & $\mathrm{X}$ & $\mathrm{X}$ & $\mathrm{X}$ & X & $\mathrm{X}$ & $\mathrm{X}$ & $X$ & X & $\mathrm{X}$ \\
\hline $\begin{array}{l}\text { Objetivos } \\
\text { econômicos }\end{array}$ & $\mathrm{X}$ & $\mathrm{X}$ & & $\mathrm{X}$ & $\mathrm{X}$ & $X$ & $\mathrm{X}$ & $\mathrm{X}$ & $X$ \\
\hline $\begin{array}{l}\text { Intencional } \\
\text { e tem efeitos } \\
\text { diretos }\end{array}$ & $X$ & $\mathrm{X}$ & $X$ & X & $\mathrm{X}$ & X & $\mathrm{X}$ & $\mathrm{X}$ & $\mathrm{X}$ \\
\hline $\begin{array}{c}\text { Não } \\
\text { intencional } \\
\text { e tem efeitos } \\
\text { indiretos } \\
\end{array}$ & & & & X & $\mathrm{X}$ & $\mathrm{X}$ & & & $\mathrm{X}$ \\
\hline $\begin{array}{c}\text { Depende } \\
\text { do grau de } \\
\text { internacio- } \\
\text { nalização }\end{array}$ & $X$ & $\mathrm{X}$ & $\mathrm{X}$ & $X$ & $X$ & $\mathrm{X}$ & $X$ & $\mathrm{X}$ & $X$ \\
\hline $\begin{array}{c}\text { Capacidade } \\
\text { de beneficiar } \\
\text { de agentes } \\
\text { privados }\end{array}$ & $X$ & & & $X$ & $\mathrm{X}$ & $X$ & $\mathrm{X}$ & $\mathrm{X}$ & $X$ \\
\hline $\begin{array}{l}\text { Capacidade de } \\
\text { resistir ao ajuste } \\
\text { do Balanço de } \\
\text { Pagamentos }\end{array}$ & $X$ & $\mathrm{X}$ & $X$ & $X$ & $\mathrm{X}$ & $X$ & $\mathrm{X}$ & $X$ & $X$ \\
\hline
\end{tabular}

nas trocas e nos fluxos de capital internacional. Essa consideração, no entanto, remete aos fundamentos do poder monetário, a dizer, à explicação das bases econômicas e políticas de sua existência e de sua diferenciação entre os agentes, o que não cabe à definição do conceito.

Outro consenso por parte das abordagens consiste no fato de que a utilizaçáo de uma moeda internacional implica em efeitos sobre os âmbitos macro e microeconômicos. Independentemente da maneira como ocorre, a utilização das moedas internacionalmente está conectada à esfera da pro- dução e da troca e à estrutura global de interação dessas atividades. Em outras palavras, pode-se dizer que os âmbitos macroeconômico e microeconômico são substituíveis sem prejuízo pela totalidade da economia global.

A consideração do poder monetário internacional como um fenômeno atrelado ao papel da moeda, que tem efeitos gerais sobre a economia e que transcende às fronteiras nacionais remete a outro elemento consensual, talvez o mais importante deles: a capacidade de postergar, adiar e repassar os custos do ajuste do balanço de pagamentos. Seja 
porque esse atributo fornece flexibilidade de política monetária, capacidade de contrair empréstimos e financiamentos, evita interrupçóes em trajetórias de crescimento ou porque permite a alocação de recursos em outras necessidades importantes, a resistência ao ajuste permite conceber e unificar a noção de autonomia e de influência trabalhada pelos autores apresentados $^{22}$.

O último elemento consensual, a questão dos objetivos políticos, é a que traz a difícil reflexão sobre o Estado como agente do poder monetário internacional. Primeiramente, deve-se conceber que a economia capitalista em termos internacionais se manifesta concretamente através da existência de um sistema político internacional onde os Estados são reconhecidos e se reconhecem como as principais unidades constituintes. Nesse complexo ambiente que caracteriza os debates em EPI, percebe-se que as questóes econômicas se confundem com as intençóes políticas dos Estados, ou seja, em certo sentido a busca pela riqueza está associada pela busca do poder em sua concepção mais ampla (KIRSHNER, 1997).

Como se nota a partir de sua definição funcionalista amplamente adotada, a utilização da moeda é, em primeira instância, um fenômeno econômi-

22. Na verdade, a capacidade de resistir às pressóes ao ajuste no balanço de pagamentos pode ser entendida de maneira mais geral a partir dos próprios fundamentos do capitalismo, o que livra o conceito de ser associado necessariamente com o balanço de pagamentos em si. A noçáo de troca traz consigo, em uma economia monetizada, a obrigação da realização do pagamento em moeda, seja ele no instante em que ocorre a transaçáo ou em um futuro determinado. Sob a lógica capitalista de acumulaçáo e considerando o respeito à noçáo de propriedade privada e à existência de incerteza na interação entre os agentes, é possível afirmar que há vantagem, por parte de um agente específico, em garantir que outros lhe paguem o mais rápido possível enquanto ele atrasa o máximo possível os seus pagamentos. Dessa forma, a capacidade de resistir ao ajuste no balanço de pagamentos é passível de compreensão análoga e fornece indícios de como se instrumentaliza o poder monetário: adiar os custos do ajuste ou repassá-los para outros agentes é a manifestação de uma capacidade de flexibilizar a obrigação dos pagamentos, o que pode ter efeitos generalizados sobre todas as trocas internacionais. Para maiores detalhes ver: Marx (1982), Brunhoff (1978) Aglietta e Orléan (1982) e Cohen (2005). co, o que dispensa a consideraçáo explícita dos objetivos econômicos no conceito, uma vez que eles são inerentes à própria dinâmica monetária global. A Economia Política Internacional, no entanto, tem como fundamento epistemológico a superação de uma visão neutra da moeda, uma herança das críticas marxista e keynesiana à economia clássica. Dessa forma, o sistema monetário internacional torna-se um espaço onde as moedas nacionais adquirem capacidade de afetar o funcionamento de economias estrangeiras e, mais ainda, de impelir Estados a decisōes políticas. Logo, as relaçôes monetárias tornam-se elementos indissociáveis da dinâmica de poder entre os Estados, ou seja, de seus objetivos políticos no cenário internacional.

Por essa razão, objetivos políticos e Estados tornam-se elementos fundamentais para a concepção de poder monetário. É possível justificar tal afirmação a partir de outras duas interpretaçôes. A primeira é que o Estado, além de unidade política internacional, possui, em termos domésticos, o monopólio da emissão de moeda através do banco central, o que lhe concede domínio sobre a esfera da circulação oficial nacional e autoridade para a promoção desse fenômeno para além das fronteiras nacionais. Ademais, sob uma ótica weberiana, o Estado exerce o monopólio do uso da força em âmbito doméstico, o que lhe garante o direito de constranger a sociedade através da violência e, portanto, a totalidade dos agentes privados caso isso seja necessário.

Ao contrário de sua intenção, a abordagem de Aronson (1978) não invalida as que centram o poder monetário no âmbito do Estado. Os bancos e os agentes privados exercem pressōes sobre os Estados para a obtenção de suas vontades particulares, seja no âmbito doméstico - onde são motivadas por grupos de interesse político - ou no âmbito externo - onde esses grupos pressionam uma ordem monetária internacional mais adequada aos seus 
interesses. Tais pressóes são reais e, em diversos casos, determinantes para a atuação internacional do Estado. Porém, o poder nelas representado, seja ele qual for, não entra na categorização de poder monetário simplesmente porque os bancos privados não emitem oficialmente a moeda nacional, um direito resguardado aos bancos centrais. Nesse sentido, os bancos e outros agentes privados podem restringir o poder monetário dos Estados, mas não parecem exercer poder monetário porque não dominam o fundamento das relaçóes monetárias internacionais e domésticas. Em outras palavras, o poder dos bancos deriva de outras fontes relacionadas, mas não da instrumentalização da moeda. Essa lógica pode ser aplicada para outros atores econômicos em geral.

A questáo se complica, no entanto, quando a realidade fornece, por exemplo, a experiência do Banco Central Europeu como a autoridade monetária responsável pela emissão do euro, o que faz questionar a autoridade do Estado sobre o exercício do poder monetário. Como se pode perceber em Drezner (2010) e em McNamara (2008), existem dúvidas acerca dos objetivos políticos por trás da internacionalização do euro. A inexistência de um projeto de internacionalização, a dizer, de uma concertação política que sustente a internacionalização do euro, dificulta enxergar a moeda como detentora de poder monetário em termos globais. Tal fato seria reversível, segundo $\mathrm{McNa}$ mara (2008), diante de uma maior integração política entre seus membros, ou seja, da redução da autoridade nacional em prol de uma autoridade supranacional no sentido geral do termo:

A política da Uniāo Europeia (UE) atual é oficialmente neutra em relação ao uso internacional do euro e, em particular, alguns tomadores de decisão temem os perigos e as pressóes que advém de uma posição internacional relevante da moeda. Mas se a EU aumentar sua integração política e sua institucionalizaçáo para o ponto onde ela pode facilmente projetar poder em termos glo- bais, o euro tende rapidamente a suplantar o dólar como a principal moeda de reserva internacional (MCNAMARA, 2008, p. 454, tradução nossa). ${ }^{23}$

Isso parece sugerir que o euro encontra-se em fase híbrida, onde o desenvolvimento do poder monetário depende de maior integração política para ocorrer. O papel desempenhado pela moeda pode ser indicativo, nesse sentido, não de poder monetário, mas sim de um grau de importância internacional exclusivamente econômica, uma vez que moeda tem suas bases em economias sólidas e é circulante em um território extenso. Embora tais fatos sejam discutíveis, não cabe a este trabalho dissertar sobre a questão específica do euro.

Voltando aos atributos do conceito, optou-se pela não inclusão dos efeitos benéficos sobre os agentes privados graças à preponderância dos objetivos políticos. Além de esses benefícios serem extremamente subjetivos, eles não podem ser providos de maneira generalizada para todos os agentes privados que influenciam na construção do poder monetário internacional referente a uma moeda ou a seu Estado emissor. Ademais, tal condição torna-se desnecessária quando o conceito pressupóe a necessidade de manutenção do grau de internacionalização da moeda, uma vez que a manutençẫo do valor internacional da moeda passa necessariamente por sua aceitação entre os agentes públicos e privados.

Finalmente, optou-se por deixar de fora do conceito a questão acerca da intencionalidade dos efeitos do poder monetário. Tal fato é explicado pela própria necessidade do conceito clássico de abranger apenas os elementos básicos necessários

23. Current EU policy is officially neutral regarding the international use of the Euro, and privately, some EU policymakers worry about the perils and pressures of being the key international currency. But if the EU does increase its political integration and institutionalization to the point where it can more readily project power globally, the Euro is likely to quickly overtake the dollar and gain key currency status. 
para sua compreensão. Uma vez que o exercício do poder monetário se dá quando uma moeda nacional passa a interferir na dinâmica econômica global e, direta ou indiretamente, permite a realização de objetivos políticos dos Estados, torna-se irrelevante para o núcleo-duro do conceito a consideração da intencionalidade das açóes.

\section{Considerações finais}

Uma das grandes dificuldades de campos de estudo multidisciplinares consiste na incapacidade de promover o diálogo entre partes cujos enfoques são diferenciados. No caso da Economia Política Internacional tais complicaçōes têm origem na formação de seus pesquisadores, que acabam seguindo uma linha de raciocínio condizente com sua trajetória acadêmica. Perspectivas mais economicistas prezam pelas variáveis econômicas e tendem a desvalorizar o papel da política e da distribuição de poder no sistema internacional. Perspectivas mais políticas, por sua vez, tendem a reduzir a importância dos fatores econômicos para a interação entre os atores internacionais. $\mathrm{O}$ resultado desse afastamento é a adoção de conceitos aplicáveis e entendíveis apenas no escopo específico dentro do qual eles foram concebidos, obstruindo, assim, o potencial de debate interdisciplinar.

Dentre diversos outros conceitos, o poder monetário internacional tende a representar a situação descrita acima: a tentativa da literatura de explicá-lo a partir da formulação de um conceito ideal parece dar continuidade a uma discussão sem fim aparente. A procura por um conceito nos moldes clássicos parece combater a dificuldade de progressão do debate que gira em torno da concepçâo de poder monetário internacional, uma vez que delimita um núcleo-duro mínimo que pode servir de ponto de partida para uma contribuição conjunta e convergente sobre o conceito. É por isso que este artigo não consiste na superação de qualquer debate sobre o conceito, mas sim na proposição de uma nova forma de abordar ideias já amplamente proferidas, de maneira a refinar a definição conceitual e promover o avanço da produção científica em EPI.

Ao considerar o poder monetário como a capacidade da moeda de alterar condiçóes econômicas internacionalmente de maneira a atingir os objetivos políticos de seu Estado emissor, garantindo o mínimo possível de prejuízos sobre sua relevância para a economia internacional e o máximo possível de resistência às pressóes relacionadas ao ajuste do balanço de pagamentos por parte do Estado emissor; e, portanto, um núcleo-duro composto por Estado, objetivos políticos, grau de internacionalização da moeda, efeitos macro e microeconômicos e resistência a ajustes no balanço de pagamentos, fornece-se o ponto de convergência da literatura da área e abre-se espaço para novas interpretaçôes, dessa vez de forma mais orientada. Apesar disso, reconhecem-se as limitações desse estudo, bem como a necessidade de promover maiores discussões e críticas relacionadas à formulação do conceito clássico de poder monetário e de outros diversos conceitos amplamente utilizados pela literatura. Partindo do conceito clássico de poder monetário internacional, a discussão teórica desta e de outras definições em EPI, assim como sua aplicação em casos específicos e tentativas de comparação assíncronas parece ser uma linha interessante a ser seguida.

\section{Referências}

AGLIETTA, Michel; ORLÉANS, Anthony. La violence de la monnaie. Paris: PUF, 1982.

ANDREWS, David M. Monetary Power and Monetary Statecraft. In: ANDREWS, David M (Ed.). International monetary power. New York: Cornell University Press, 2006. p. 1-28.

ARONSON, Jonathan David. Money and power: banks and the world monetary system. [S. 1.]: SAGE Publications, 1978. BRUNHOFF, Suzanne de. A moeda em Marx. Rio de Janei- 
ro: Paz e Terra, 1978

COHEN, Benjamin Jerry. The Macrofoundations of Monetary Power. In: EUI Working Paper RSCAS No 2005/08, San Domenico de Fiesole, 2005. Disponível em: <http:// www.polsci.ucsb.edu/faculty/cohen/working/pdfs/CohenMonPower.pdf $\geq$ Acesso em: 09 jul., 2016.

COHEN, Benjamin. International Political Economy: an intellectual history. Princeton: Princeton University Press, 2008.

COHEN, Benjamin Jerry. Currency and state power. Santa Barbara: POLSCI, jan. 2011. Disponível em: <http:// www.polsci.ucsb.edu/faculty/cohen/working/pdfs/Krasner_ Rev_1-11.pdf $\geq$ Acesso em: 09 jul. 2016.

COHEN, Benjamin Jerry. Money, power, authority. Santa Barbara: University of California, July 2014. Disponível em: <http://web.isanet.org/Web/Conferences/FLACSO-ISA\%20 BuenosAires\%202014/Archive/727c6f68-1528-4441-b0f7-98a5adc82ab2.pdf $\geq$ Acesso em: 09 jul. 2016.

DREZNER, Daniel W. Will currency follow the flag? International Relations of the Asia-Pacific, v. 10, n. 3, p. 389-414, 2010.

FONSECA, Pedro Cezar Dutra. Desenvolvimentismo: a construção do conceito. In: INSTITUTO DE PESQUISA ECONÔMICA APLICADA. Brasília: IPEA, 2015. [Texto para Discussão, 2103] Disponível em: <http://www.ipea.gov.br/portal/ images/stories/PDFs/TDs/td_2103.pdf $\geq$ Acesso em: 09 jul. 2016 HELLEINER, Eric. Below the state: Micro-level monetary power. In: ANDREWS, David M (Ed.). International Monetary Power, Cornell University Press, p. 72-90, 2006.

HELLEINER, Eric; KIRSHNER, Jonathan (Ed.). The future of the dollar. Cornell University Press, 2009.

KIRSHNER, Jonathan. Currency and coercion: the political economy of international monetary power. Princeton University Press, 1997.

MARX, Karl. Para a crítica da economia política: salário preço e lucro: o rendimento e suas fontes. São Paulo: Abril Cultural, 1982.

MCNAMARA, Kathleen R. A rivalry in the making? The Euro and international monetary power. Review of International Political Economy, v. 15, n. 3, p. 439-459, 2008.

NORRLOF, Carla. Dollar hegemony: A power analysis. Review of International Political Economy, v. 21, n. 5, p. 10421070, 2014.

SARTORI, Giovanni. Concept misformation in comparative politics. American political science review, v. 64, n. 04, p. 1033-1053, 1970.

SARTORI, Giovanni. Guidelines for concept analysis. In: Social science concepts: A systematic analysis, p. 15-85, Beverly Hills: SAGE, 1984.

STRANGE, Susan. States and Markets. 2. ed. London: Continuum. 1998.
WEBB, Michael C. Capital mobility and the possibilities for international policy coordination. Policy Sciences, v. 27, n. 4, p. 395-423, 1994.

WEYLAND, Kurt. Clarifying a contested concept: populism in the study of latin American politics. Comparative politics, v. 34, n. 1, p. 1-22, Oct. 2001 